\title{
Cultura, economia, política e saber como espaços de significaçáo na Terapia Ocupacional Social: Reflexóes sobre a experiência do Ponto de Encontro e Cultura
}

\author{
Denise Dias Barros ${ }^{a}$, Debora Galvani ${ }^{b}$, Marta Carvalho de Almeidac ${ }^{c}$, Carla Regina Silva Soares ${ }^{d}$ \\ a'Doutora em Sociologia, professora do Departamento de Fisioterapia, Fonoaudiologia e Terapia Ocupacional, \\ Universidade de São Paulo - USP, São Paulo, SP, Brasil. Professora do Programa de Pós-graduação em Terapia \\ Ocupacional da Universidade Federal de São Carlos - UFSCar, São Carlos, SP, Brasil \\ ${ }^{b}$ Doutoranda em Psicologia, terapeuta ocupacional, Departamento de Fisioterapia, Fonoaudiologia e Terapia \\ Ocupacional, Universidade de São Paulo - USP, São Paulo, SP, Brasil

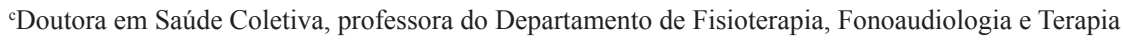 \\ Ocupacional, Universidade de São Paulo - USP, São Paulo, SP, Brasil \\ ${ }^{\mathrm{d}}$ Mestranda em Psicologia Social, terapeuta ocupacional do Departamento de Fisioterapia, Fonoaudiologia e \\ Terapia Ocupacional, Universidade de São Paulo - USP, São Paulo, SP, Brasil
}

Resumo: Trata-se da descrição e análise da experiência do Ponto de Encontro e Cultura - PEC, desenvolvido pelo Projeto Metuia - Universidade de São Paulo (USP-SP) entre 2007 e 2011, em São Paulo, SP, articulando a Terapia Ocupacional às áreas de produção cultural. Ela envolveu pessoas em situação de rua, terapeutas ocupacionais e estudantes de Terapia Ocupacional. A leitura de diferentes dimensões da experiência foi conduzida pela noção de espaço de significação. Tomamos o espaço enquanto campo capaz de servir de articulador e de interpretação do real, em que relações e ações potencializam as quatro esferas da ação em Terapia Ocupacional que focalizamos: a cultura, a economia, a política e o saber. Compreendemos que o esforço coletivo de construção permanente do PEC foi o de evidenciar suas características como pedaço, ou seja, transformando-se em um ponto de referência comum no qual estão em jogo sociabilidades que se estabelecem pelo manejo de símbolos e códigos comuns. Assim, notamos que, partindo do espaço da cultura, é possível tecer articulações com a economia, a saúde, a assistência social, a política e a produção de conhecimentos.

Palavras-chave: Cultura, Política, Atividades Humanas, Pessoas em Situação de Rua.

Autor para correspondência: Denise Dias Barros, Universidade de São Paulo - USP, Rua Cipotânea, 51, Cidade Universitária Armando de Salles Oliveira, Butantã, CEP 05360-000, São Paulo, SP, Brasil, e-mail: ddbarros@usp.br 


\title{
Culture, economics, politics and knowledge as meaning-spaces in Social Occupational Therapy: reflections on the experience of "Ponto de Encontro e Cultura"
}

\begin{abstract}
This article describes and analyzes the "Ponto de Encontro e Cultura - PEC", an experience developed by METUIA - University of São Paulo (USP-SP) in São Paulo from 2007 to 2011 which linked occupational therapy to areas of cultural production. It was attended by the homeless, occupational therapists and students of occupational therapy. To perform the analysis of the different dimensions of the experience we were guided by the meaning-space notion. We took the space as an organizer to understand a reality in which relationships and actions are being empowered in four different spheres: culture, economics, politics and knowledge. We noted that this practice showed that there was an ongoing collective effort to build what may be called piece. This characterizes a process where the space is a common reference point which brings into play different modes of sociability that are created by the management of common symbols and codes. It was important to recognize and appreciate the plurality of modes of knowledge. Thus, we observed that, from the cultural sphere, it is possible to articulate economics, health, social assistance, politics, and knowledge production.
\end{abstract}

Keywords: Culture, Politics, Human Activities, Homeless.

\section{Introdução}

Nós fazemos prática, primeiro a prática e depois a teoria. Não fazemos antes a teoria e depois a prática porque isso seria um caminho muito mais reacionário do que pensam; a teoria é o a priori científico: do velho pensamento científico. [...] Não tivesse aceitado esse risco, estaria reciclando inevitavelmente a teoria antiga, aquela dos textos e dos manuais intelectuais dos quais provenho. Eu teria sofisticado uma forma de narcisismo intelectual, teria traduzido as novas experiências dentro de um código e uma linguagem que permaneceriam o mesmo ${ }^{1}$.

"Nós fazemos a prática e depois teoria" é a premissa herdada de Franco Basaglia (BASAGLIA apud ROTELLI, 1983) sobre a qual caminhamos neste texto, a fim de percorrer pela descrição e análise as principais reflexóes que nos orientaram ou que foram produzidas na experiência do Ponto de Encontro e Cultura - PEC, desenvolvido pelo Metuia - Universidade de São Paulo (USP) entre 2007 e 2011, em São Paulo. Iniciativa conjunta decorrente de parcerias e trabalhos anteriores com os movimentos organizados de um segmento da sociedade brasileira a que se convencionou chamar de pessoas em situação de rua, ela é igualmente expressão do esforço de interação entre ensino, pesquisa e extensáo universitária no contexto da Terapia Ocupacional Social. Soma-se a reflexôes desenvolvidas por Ghirardi (2011), para quem é prioritário um percurso formativo com enfoque em processos econômico-sociais, além do fortalecimento das relaçóes democráticas e da experiência comum com foco no fazer quotidiano conforme definido por Certeau (1998).

No artigo 207 da Carta Constitucional do Brasil, lê-se que as universidades

[...] gozam de autonomia didático-científica, administrativa e de gestão financeira e patrimonial, e obedecerão ao princípio de indissociabilidade entre ensino, pesquisa e extensão de um setor [...] (BRASIL, 1988).

A extensão universitária tem sido um campo de aprendizado constante. É definida no Plano Nacional de Extensão Universitária como

[...] processo educativo, cultural e científico que articula o Ensino e a Pesquisa de forma indissociável e viabiliza a relação transformadora entre Universidade e Sociedade. (FÓRUM..., 2001, p. 5)

No caso da Terapia Ocupacional Social, a extensão universitária forneceu assim o aparato institucional indispensável para que buscássemos responder à necessidade de construir espaços inovadores para alimentar também o ensino e a reflexão, muito deficitários no campo específico. A experiência do Ponto de Encontro e Cultura - PEC procurou responder ainda ao exercício da premissa de que a ação técnica permanece inseparável da ação política, em que a coerência e o engajamento político e social ocorrem pelo aprofundamento de questóes bem definidas, a fim de receberem estudos e análise detalhados e contextualizados.

Retomamos, de um lado, as noçóes de pedaço, trajeto e circuito desenvolvidas por Magnani (2002) já presentes e publicadas em outras reflexôes 
do Metuia (GALVANI; BARROS, 2010). Essa definição de território é revisitada e transformada no sentido de favorecer a leitura de outra ordem de questôes suscitadas pela reflexão da experiência. De outro lado, trabalhamos com a noção de espaço de significação como articuladora de nossa leitura. Essa noçấo desenvolve-se em nosso percurso como forma de permitir mais amplitude teórica à noçâo de território, considerado como lócus material e simbólico da construção histórica, do pertencimento, da ação política e da intervenção, ou seja, do lugar da formação técnica do intelectual que é técnico-político (GRAMSCI, 1995). Essa pedagogia crítica aliada à sua concepção política da cultura nos aproxima das concepçóes de Paulo Freire (1975, 1987a, 1987b), para quem há uma unidade inseparável entre ação e ideia.

Marc Augé (1994) evoca o lugar antropológico como sendo significativo para os que nele habitam e para quem procura compreendê-lo, possuindo, assim, uma dimensão de inteligibilidade. Pierre Lévy (1997) sugere que a humanização é processo aberto e que o homo sapiens caminha dentro de um novo espaço do saber, em que se articulam novas maneiras de construir os coletivos inteligentes e de valorizar a diversidade das qualidades humanas. Para ele, um espaço antropológico corresponde a um sistema de proximidades (espaço) próprio ao mundo humano (antropológico), portanto, vinculado a técnicas, linguagens, convenções sociais e a tecnologias da política, que interrogam as configuraçôes contemporâneas do laço social, da construção e reconfiguração da coesão social, das interaçôes pessoais e coletivas, as maneiras de se religar coletivamente frente às expectativas existenciais de nossos dias (BOUVIER, 2005). E é a partir desses autores que começamos a propor aqui a noção de espaço de significação para a leitura de dimensóes da experiência do Ponto de Encontro e Cultura.

Elaboramos essa reflexão a partir da noção de espaço de significação apreendido em diferentes perspectivas de análise. Tomamos o espaço como campo capaz de servir de articulador e de interpretação do real, em que relaçôes e açôes potencializam as três esferas da ação em Terapia Ocupacional que focalizamos: a cultura, a economia e a política. Além dessas, o espaço do saber configura-se como uma quarta esfera em que a reflexão, a formação profissional e a produção do conhecimento entrecruzam-se, revelando um entendimento particular da relação entre universidade e sociedade e o permanente questionamento sobre a relação entre quem ensina e quem aprende, além da interrogação sobre o que é conhecimento, como, para quem e com quem é produzido. $\mathrm{Na}$ análise da experiência, a formação e a produção do conhecimento são constantes e perpassam os diferentes espaços.

\section{Nós do ponto}

\subsection{Descrevendo o Ponto de Encontro e Cultura (PEC)}

O Ponto de Encontro e Cultura caracterizou-se como um espaço de articulação e encontro entre diversos saberes e linguagens de expressão cultural, construído por profissionais do Projeto Metuia/USP, lideranças do movimento da população em situação de rua, artistas, estudantes ligados ao Curso de Terapia Ocupacional da USP, vendedores e voluntários da Organização Civil de Ação Social (OCAS) ${ }^{2}$ e outras pessoas da comunidade.

O espaço - como ambiente de criação e expressão cultural, artística, política e de saberes - nasceu da compreensão compartilhada sobre a importância do laço social construída ao longo de anos anteriores no trabalho com pessoas e grupos em situação de rua ou em permanente interação com a rua. Observamos que as redes de pertencimento se tecem sobre dimensóes complementares da política, religiosidade, educação, cultura e trabalho, as quais alavancavam experiências, trazendo novas perspectivas de vida. A articulação com a Associação Rede Rua ${ }^{3}$ nos levou em 2007 à aproximaçáo com a OCAS, que nos cedeu espaço de trabalho em uma casa no bairro do Brás que, à época, era sua sede (o que se mantém até então) e do Movimento dos Trabalhadores Rurais Sem Terra (MST). A dinâmica de apropriação da casa foi modificada com os novos projetos sociais. Entre 2010 e 2011 a casa sediou, ainda, o Movimento Nacional da População de Rua (MNPR), a Ouvidoria Comunitária da População de Rua e o Ponto Cultural OCAS.

A presença de terapeutas ocupacionais e estudantes do Projeto Metuia ativos na costura política e de laços sociais para ampliar e fortalecer diferentes circuitos de participação social, cultural e de convivência de pessoas em situação de rua possibilitou uma série de alianças que alicerçaram a construçáo inicial do PEC.

Construímos a seguir uma narrativa em forma de descrição que busca reconstituir "um dia no PEC", no intuito de relacionar experiências, açôes e reflexôes mais pontuais e particularmente pertinentes em seu contexto de emergência. $\mathrm{Na}$ experiência, os espaços de significação estão mesclados, entrelaçados, podendo ser mais ou menos fortes segundo a situação, os temas emergentes ou as questóes em pauta. 


\subsection{Situação 1: Um dia no PEC}

Já chegam às 16h! Como era costume, os frequentadores do "ponto" (apelido de nosso PEC) costumavam aglutinar-se na calçada da casa do Brás. Alguns haviam se encontrado na estaçáo do metrô e conversavam pelo caminho, outros chegariam depois de fóruns e assembleias, após concluir o dia de trabalho ou mesmo o curso de filosofia do projeto Trecho 2.0. Já era possível iniciar algumas açôes, já que os integrantes do MNPR - que faziam suas reunióes antes do PEC - as estudantes da TO e a meninada da casa ao lado, também haviam se aproximado e davam continuidade a assuntos de outros dias. Sim, tantos foram os trajetos, os circuitos e os pedaços que se cruzaram e se redefiniram nesses encontros! Íamos assim, aos poucos, aqueles que ainda permaneciam na calçada, juntavam-se a quem se encontrava na sala multimídia, no quintal, para dirigirem-se para a sala de reunióes e a cozinha. Dinâmica que se repetia: pequenos grupos com diversos interesses e necessidades preenchiam a casa de espaços de sentidos.

Naquele dia, o grupo que chegou mais cedo acolheu Lucélia, que passava pela rua e observou a movimentação naquela casa. Ela acabara de sair da sede da Igreja Mundial do Poder de Deus, vizinha da casa do Brás, local que frequentava e em que fazia vigílias noturnas, em especial quando não conseguia vaga em albergue ou outra forma de moradia. Os participantes do PEC mobilizavam-se em torno de informaçôes para poder ajudá-la a conseguir vaga de pernoite em um albergue ao mesmo tempo em que explicavam sobre aquela casa: a possibilidade de vender a Revista Ocas, as açóes do MNPR, a Ouvidoria Comunitária, a programação cultural e as possibilidades do PEC.

Uma roda de conversa se formou em torno do projeto Virada Cultural. A Secretaria de Cultura do Município de São Paulo abrira inscriçôes para artistas e grupos para integrar a programação desse evento que promove 24 horas de programação cultural gratuita uma vez ao ano. Decidiu-se, assim, que haveria inscriçôes individuais e o PEC se inscreveria na categoria "a cidade como cenário", com a proposta de coordenar um sarau. Rumávamos para um reconhecimento público e de maior abrangência! A experiência da organização de saraus, amadurecida em anos de atividades na casa do Brás e em outros espaços da cidade, dava aos integrantes do PEC o sentimento de união e o ânimo do novo passo. Muitos eram os desafios, mas um grupo assumiu a liderança da proposta com estudantes de TO e logo a agenda própria para a elaboração do projeto foi construída. Sua produção, norteada pelo formulário que demandava a descrição do evento e o histórico do grupo, exigiu um trabalho de memória, reflexão coletiva e tradução, no sentido de dar uma linguagem escrita ao que experimentávamos nos saraus.

Enquanto isso, o grupo que estava na cozinha assumia a coordenação e o preparo do menu do dia. Havia entre eles um cozinheiro profissional nascido no Chile e um dos mais assíduos frequentadores que costumava assumir a produçáo da alimentação: juntos trabalharam. Santiago falava de culinária e de sua vida de viajante que se encanta com experiências culturais sobre as quais tem prazer de falar. Essas trocas se traduziram em um risoto com temperos exóticos - produzido dentro do limite orçamentário de cerca de $\mathrm{R} \$ 40,00$ - e nas histórias de suas viagens e de seus aprendizados, como a formação em medicina oriental. A cozinha do PEC tornou-se um dos poucos espaços onde desenvolvia essa atividade tão central em sua vida noutros tempos e lugares, já que ele estava vivendo entre o albergue, o trabalho e a rotina de tratamento do câncer.

Outras pessoas checavam seus e-mails e navegavam pela internet na sala multimídia, recém-reformada com a verba recebida do Ministério da Cultura, através do Programa Cultura Viva - Ponto de Cultura. O assunto em pauta era o AcampaSampa. E-mails, blogs e reportagens foram compartilhados, estimulando as pessoas a se debruçarem sobre a compreensão dos significados desse movimento mundial que tem como reivindicação principal a defesa da democracia participativa. Assim, diferentes posições político-ideológicas foram lançadas num debate que se tornou intenso. Somada à curiosidade das estudantes as discussóes levaram o grupo a visitar o AcampaSampa. Desejávamos conhecer de perto tal iniciativa, além de contribuir com doaçôes.

Já passava das $21 \mathrm{~h}$ e aos poucos nos mobilizávamos para encerrar a programação daquele dia, algumas propostas se concretizaram e outras ficaram pendentes, aguardando novos encontros.

Acreditamos que é possível depreender uma série de reflexóes e de possibilidades de leitura dos eventos descritos, os quais resultam de combinaçóes em grande número de relaçóes e de práticas sociais diferenciadas. As atividades do PEC estendem-se para fora do espaço da casa e do tempo da reuniáo, pois inúmeras atividades com cada pessoa ou subgrupos são criadas a fim de realizarem-se os encaminhamentos necessários. A integração constante entre estudantes de Terapia Ocupacional da USP, que se renovam a cada semestre, e o espaço de troca de saberes e afetos constituído pelo PEC possibilitou o encontro entre diversos modos de vida e circulação 
pela cidade de São Paulo. No "ponto", as noites de segunda-feira eram dia de encontro marcado com um garoto tímido de apenas 18 anos, que muito sabia sobre a vida na rua. Fabinho adorava cantar rap e dividir com os amigos do PEC suas rimas e poesias. No contato com os frequentadores assíduos e com os novos integrantes, apesar da timidez, Fabinho estava sempre interessado em acolher e se aproximar. Os mais velhos preocupavam-se com ele: não pernoitar na rua, não se envolver em situaçốes de perigo..., e ele, ainda aprendiz da vida, estava sempre conectado com os projetos individuais e coletivos, disposto a colaborar. Em meio a tantos projetos, Fabinho também queria dar vida ao seu: gravar um CD de rap e escrever um livro autobiográfico.

Certo dia, as estudantes de Terapia Ocupacional participariam de uma atividade denominada Circuitos em São Paulo: conhecendo diferentes perspectivas da cidade, monitorada por participantes do PEC que voluntariamente se disponibilizavam a visitar espaços da cidade relativos às suas práticas cotidianas. Como já era de se esperar, Fabinho se prontificou a levar-nos ao seu local de trabalho: a cooperativa de catadores de material reciclável.

Naquela tarde, no caminho da Praça da Sé até o Glicério, Fabinho atribuiu novos sentidos a antigos circuitos da cidade. Nesse trajeto conhecemos marcas de sua história, valores e aspiraçôes. Abriu-se espaço para o diálogo, a escuta, o conhecimento mútuo e a troca de saberes que propiciam, assim como proposto por Freire (1987a, b) a relação dialógica e a real compreensão do homem dentro de seu contexto, considerando sua cotidianidade como ponto de partida, para que, junto dele, sejam traçados novos rumos e trajetórias. Além disso, a experiência de partilhar os espaços reais de vida cria laços de afeto imprescindíveis à identificação com o outro e à disponibilidade de estar junto na construçáo dos projetos de vida. Propomos a seguir uma (re)leitura de camadas que se movem, ora se sobrepondo, ora se diferenciando sobre/entre os espaços de significação da cultura, da economia e da política.

\section{Dimensões e perspectivas de leitura e de compreensão da experiência}

\subsection{O PEC como espaço da cultura}

O espaço da cultura forma o ambiente dos laços sociais e das alianças em diferentes domínios da vida social, do fazer que nos religa a todos na exigência existencial da produção de sentido. É, assim, um campo em que o alimento intelectual constitui-se indissociavelmente da vida afetiva e produtiva (em termos econômicos e políticos). Por meio dela, dimensôes relevantes vão se impondo à observação e análise: religiosidade, a expressão artística, do dizer de si, a narrativa e mesmo uma articulação inseparável do fazer da história e dos laços entre singularidades e coletivo, do fazer econômico e do fazer político.

O recorte de apresentação neste texto valoriza a dimensão da literatura no PEC, seja ela oral ou escrita. Os músicos, escritores, poetas e pessoas que circulam por saraus e outros espaços culturais da cidade deram ao PEC uma configuração artística central. Nascia na casa do Brás, um espaço de expressão no qual aconteceram leituras, performances musicais e teatrais. Os saraus do PEC, abertos à comunidade e divulgados nas redes de relaçôes de seus produtores, caracterizaram-se como momentos de expressão da produção literária apresentada em diferentes formatos, como as poesias, as letras de música, textos para teatro e os textos analíticos e críticos.

Dia de sarau era dia de grande movimentação, nos quais aos participantes assíduos se somavam muitos convidados, visitantes e alguns artistas habitués dos circuitos dos saraus da cidade. $\mathrm{Na}$ situação 2, Marcela Nardo (2008), estudante de Terapia Ocupacional, descreveu um dia de festa e sarau no PEC. Tratou-se de pensar o PEC, cuja participação e atividades estiveram comumente centradas no universo adulto, como espaço das crianças, fossem elas nossos filhos ou os vizinhos da casa. Buscou-se valorizar e estimular a convivência intergeracional e, sobretudo, garantir espaços de permanência e participação das crianças.

\subsection{Situação 2 - Sarau e festa das crianças $^{4}$}

Eram quase cinco da tarde quando demos início à reunião acerca do evento I Seminário Internacional África em Movimento, a ser realizado na próxima semana. Havíamos decidido coordenar uma banca de venda de livros e da Revista Ocas e nessa reunião trabalhamos no sentido de dividir as tarefas e estabelecer acordos sobre a gestão financeira decorrente das vendas. Alguns participantes sugeriram que tivéssemos contato com os livros que seriam vendidos para que, ao apropriar-se minimamente do conteúdo, facilitássemos o contato com os compradores. Em seguida, partimos para os preparativos da festa. Fomos ao mercado comprar os ingredientes para o preparo de cachorros-quentes 
e pipoca. Já de volta, dividimos as tarefas entre o preparo do molho da salsicha e o café. Outro grupo se incumbiu de dar início à diversão, ao entreter as pessoas que já estavam no local. Não posso descrever exatamente as brincadeiras que faziam, mas os risos que ouvíamos da cozinha nos contagiavam e despertavam a nossa curiosidade. O PEC recebeu a visita de pesquisadores que estavam em São Paulo em virtude do evento citado. Foi interessante observar o interesse e a curiosidade que o encontro despertou, em especial entre o pesquisador egípcio e os participantes do PEC.

Uma parte do lanche já estava pronta, então resolvemos descer. Devo confessar que quando adentrei a sala onde acontecem nossos encontros fiquei admirada com a quantidade de pessoas que ali estavam: aos frequentadores das reuniôes se somavam crianças moradoras das proximidades da sede da OCAS. Preparamos os lanches embalados por músicas infantis, enquanto nos preparávamos para a realização do sarau. Pilar deu início à apresentação recitando pequenas histórias infantis seguidas por uma poesia de sua autoria. Seu filho Pedro, na época com 12 anos, também recitou algumas de suas produçôes e cantou algumas músicas junto com a irmá Dandara (5 anos). Eu recitei um poema de minha autoria. Várias pessoas leram poesias e histórias, inclusive em língua espanhola, contemplando a diversidade do grupo.

Ainda que a produção literária seja mobilizadora entre nossos pares, ela raramente conseguiu transpor barreiras de classe, que são também barreiras espaciais, sendo possíveis existirem no circuito alternativo. Algumas tentativas de transpor tais separaçóes foram realizadas. Certa vez a Galeria Olido 5 cedeu espaço ao PEC para o lançamento do CD de músicas sertanejas de Montreal, dialogando com o sarau de poesias de cordel organizado pelo Ponto de Leitura da própria Galeria Olido. Em outro momento promovemos a organização de um sarau do PEC, com divulgação e venda coletiva da Revista Ocas, além do lançamento do livro de poesias Palavras Inacadêmicas, de autoria de Pilar, na renomada galeria do centro da cidade. Dessa forma, o PEC e seus artistas entravam para a programação cultural da cidade de Sáo Paulo em um espaço notadamente da cultura, ampliando as possibilidades de troca, inclusive financeiras, e ressignificando sua própria identidade cultural. A itinerância tornou-se uma estratégia do PEC, sendo marcada, entre outras, pela presença nos saraus da Galeria Olido, no projeto Letras em Cena no MASP ${ }^{6}$ e em eventos culturais gratuitos da cidade que despertavam interesse especial dos participantes por sua relação com a literatura. As açóes do PEC dimensionaram-se tanto no sentido de estimular e proporcionar acesso a circuitos culturais da cidade - circuitos esses alimentados pelas trajetórias dos participantes -, muitas vezes dificultado pelas distâncias geográficas ou mesmo pela discriminação. Mesmo assim, as atividades fortaleceram-se e o grupo acumulou experiência para investir em seu reconhecimento como espaço de produção de eventos culturais (saraus, debates, projeção de filmes na rua, entre outros), integrando-se ao circuito cultural de São Paulo (MAGNANI, 2002). Por concurso de edital público, o PEC institucionalizou-se como programaçáo do Ponto de Cultura OCAS, integrando a iniciativa do Ministério da Cultura.

O PEC preocupou-se igualmente com a dimensão do trabalho e da vida econômica de seus participantes. As rodas de conversa eram momentos de trocas intelectuais, pessoais e busca de parcerias mais diversas e amplas. Delas surgiam ideias, algumas foram materializadas. Esse foi o caso da Casa das Áfricas. A parceria entre o Projeto Metuia e a Casa das Áfricas ${ }^{7}$ aproximou o PEC do I Seminário Internacional África em Movimento: Interconexões e desconexôes de saberes ao Sul. Tal aproximação desdobrou-se em algumas açóes como o agenciamento coletivo no PEC para a produçáo da barraca de venda de livros dos palestrantes e da Revista Ocas durante o evento (ver situação 1), além da realização de rodas de conversa no $\mathrm{PEC}^{8}$, com a presença de pesquisadores africanos. As temáticas para as rodas de conversa foram produzidas a partir da curiosidade, de sugestôes dos participantes e das oportunidades que surgiam. Certa vez, a roda organizou-se em torno da história e da cultura egípcias, do movimento político de jovens e de leituras críticas sobre a situação do oriente médio. A temática envolvia igualmente a culinária, que naquele dia seria árabe. Um pequeno grupo decidiu fazer o registro fotográfico e escrito, que apoiaria, posteriormente, a publicação de um artigo no jornal $O$ Trecheiro 9 . A produção jornalística coletiva do PEC ganhou espaço nas publicaçóes da Revista Ocas e no jornal O Trecheiro.

\subsection{O PEC como espaço da economia}

O espaço da economia circunscreve dimensóes múltiplas da produçáo da vida, campo privilegiado do reconhecimento da interdependência humana (ELIAS, 1994), da troca, da rede de suporte e do tecer da pragmática da vida, espaço articulador das possibilidades de ser.

A preocupação com as trocas econômicas manteve-se sempre conectada com as ações do 
PEC, tanto na dimensão da produção individual, como no agenciamento coletivo. Uma preocupação constante foi a venda da Revista Ocas, expressa pelos vendedores participantes do PEC, alguns com bastante experiência, outros iniciando suas atividades na venda. O PEC constituía-se como espaço de troca de informaçôes que potencializavam as vendas, como as constantes sugestôes de locais para venda e melhores estratégias de abordagem dos leitores. As sugestôes e demandas que surgiam eram, no geral, referentes ao agenciamento para abertura de espaços de venda. Certa vez, uma vendedora recebeu o convite de um de seus leitores para participar do evento de abertura das atividades do Instituto Vladimir Herzog (IVH), que ocorreria na Cinemateca de São Paulo. A proposta chegou ao PEC e despertou grande interesse nos participantes, tanto pelo tema em questão, quanto pelos desdobramentos que se vislumbravam com esse contato. Em reunião no PEC, algumas ideias surgiram e encaminhamos as seguintes propostas, que se concretizaram de forma articulada: assistir ao filme Vlado - 30 anos depois - pensada como uma estratégia de nos informar e nos conscientizar sobre o processo da ditadura brasileira e como referência para o debate; convidar integrantes do IVH para uma roda de conversa no PEC; e negociar a liberação para a venda da revista no evento. Registros fotográfico e escrito acompanharam todos os acontecimentos e eles culminaram na escrita coletiva de artigo publicado na seção "Cabeça sem teto" da Revista Ocas, comumente dedicada à produção dos vendedores. Alguns vendedores avaliavam, inclusive, que a publicaçáo de reportagens e textos de sua autoria era um facilitador para a venda da revista e abordagem dos leitores. A produção literária torna-se espaço para recontar a história produzida no PEC para novos interlocutores e expressão política do grupo.

As alternativas econômicas formam um campo fundamental de açôes cuja abordagem se organiza em frentes simultâneas e integradas no percorrer de cada itinerário singularizado da açấo em Terapia Ocupacional Social junto à pessoas, grupos ou comunidades com as quais se trabalha. Vale ressaltar aqui, como exemplo, o esforço coletivo para inscrição e realização do concurso público para agente comunitário de saúde, a fim de compor equipes de saúde da família para atendimento às pessoas em situação de rua na cidade de São Paulo. As etapas do concurso foram superadas, passo a passo, coletivamente: da leitura e compreensão do edital à inscrição pela internet, que colocava algumas barreiras importantes, ao debate sobre o Programa de Saúde da Família, que seria um dos temas da prova, à valorização da experiência com a rua, que poderia ser explorada nas dinâmicas de grupo e entrevistas. Quatro dos integrantes do PEC foram aprovados e três assumiram o trabalho. Na situação 3 descrevemos uma cena ligada a esse evento.

\subsection{Situação 3: Desafios e improvisos}

Recebemos uma ligação no horário do PEC de Alice, trabalhadora da Associação Saúde de Família, que nos informou sobre o concurso que essa instituição promoveria para agente comunitário de saúde. Ela, que já conhecia alguns vendedores da Revista Ocas e o PEC, incentivou os participantes que tivessem ensino médio completo a se inscrever. Acreditava que poderiam contribuir sobremaneira com o trabalho que seria realizado com foco na população em situação de rua. Entramos em alvoroço pensando formas de superar as etapas da inscrição, porém alguns ficaram muito desapontados por não possuir ensino médio, o que virou motivo de reflexão por parte do grupo: seria interessante investir na educação pessoal? Quais os impedimentos para conseguir ingressar no ensino formal? Quais as oportunidades que existiam para as pessoas com idade avançada e com baixo nível de escolaridade? A euforia se misturou à frustração! A documentação pessoal incompleta foi outro desafio, algumas pessoas solicitaram apoio e orientação para conseguir obtê-la.

A inscrição precisava ser feita pela internet. Não sendo possível ali, decidiu-se ir até um ponto de acesso público. Não havia tempo a perder, então, no dia seguinte, trabalhamos em uma lna house do centro da cidade. Com a documentaçáo em mãos, pudemos nos dedicar à leitura do edital e condiçóes de inscrição. Todos cooperaram e conseguimos terminar as inscriçôes no limite do tempo! Restava, agora, acompanhar as outras fases do concurso.

Nos exemplos anteriores ficaram explicitados agenciamentos coletivos, mas a eles somam-se as produçóes pessoais mais singularizadas. Destacaremos aqui alguns agenciamentos realizados a fim de viabilizar a produção literária de Pilar, que se apresenta como vendedora da Revista Ocas, poetisa e agitadora cultural. As atividades em Terapia Ocupacional emergem da leitura de necessidades e de prioridades em determinado contexto de significação e possibilidades, elas se compóem baseadas na interlocução e nas possibilidades do real. Foi assim que, no PEC, cuidados específicos com sua produção pessoal aliaram-se aos processos coletivos. Um exemplo foi a produção de um livro de poesias com imagens de sua trajetória. Adriana, bolsista da USP, e a estagiária Olívia articularam-se com profissionais em edição de textos para - a partir das sugestóes 
da Pilar e das possibilidades técnicas - chegar à impressão do livro. Nos agradecimentos do seu livro, Pilar ressalta a importância da produção intelectual pautada na sua experiência e na parceria:

Agradeço a todos que colaboraram com esse livro. A princípio, apenas folhas de xerox para brincar. Depois de passar por tantas mãos intelectuais, eis que surge essa obra de arte. Todos que participaram são de muitíssima importância, especialmente o grupo METUIA que, partindo de um Ponto de Encontro, depois de muitos encontros, percebeu que as Palavras Inacadêmicas não poderiam permanecer apenas em folhas de xerox, precisavam virar livro, para levar aos olhos e ouvidos "letras" para quem tanto aprecia a arte. Também é preciso notar que realmente não é necessário academia de letras para ser um grande poeta ou escritor e, sim, levar em conta os dons dados pela própria natureza (FERREIRA, 2009, p. 01).

O Projeto Metuia-USP conseguiu financiamento para que as primeiras impressôes fossem realizadas e em parceria com a Ocas, a Galeria Olido e participantes do PEC, realizou-se o lançamento do livro, com um sarau coordenado por Pilar e o grupo Raizarte. Esse, uma iniciativa de Pilar e seus filhos para desenvolver atividades de criação poética e cultural, como saraus em bares e espaços culturais. Em tais ocasiōes, Pilar vende a Revista Ocas, os livros de poesia e fortalece os potenciais artísticos e econômicos do grupo. Mãe e filhos, todos poetas, dedicam-se à poesia engajada na busca de valorizaçáo e conquistas de direitos da mulher, do negro, do morador das periferias, das pessoas em situação de rua, entre outras. Novos projetos surgiram, ente eles a produçáo de um livro autobiográfico, que conta com a leitura e discussão de seus diários, assim como entrevistas com foco na sua história de vida ${ }^{10}$. O processo envolve reunióes periódicas com entrevistas, além de leitura e discussão de seus diários.

A história e nosso trabalho com Pilar explicitam não apenas uma trajetória, mas igualmente diversas articulações entre os diferentes espaços de significação aqui considerados, ou seja, da cultura, da economia, da política e do saber.

\subsection{O PEC como espaço da política e construção ativa do bem comum}

O espaço da política corresponde tanto ao fazer político enquanto ação comum, às iniciativas em que se trabalha a própria consciência de grupo, quanto ao fazer política como a ação de um segmento social que se organiza para adquirir voz e reconhecimento social. Ou seja, para se construir como interlocutor necessário e incontornável tanto no diálogo com os gestores das políticas de Estado como com a sociedade de forma mais ampla. Do espaço da política, realçamos aqui os esforços para se pensarem soluçóes com base em perspectivas internas ancoradas na compreensão das dimensóes histórico-políticas e existenciais das experiências das pessoas em situação de rua.

Lideranças de diferentes movimentos sociais como os Movimentos Nacional e Estadual da População em Situação de Rua, Movimento Estudantil, Movimentos de luta por moradia, Marcha Mundial das Mulheres, Movimento dos Sem Terra, entre outros, participaram da construção cotidiana do PEC. Além disso, reuniram-se pessoas com posiçóes políticas diferentes, por vezes conflitantes ou em disputa por hegemonia política. Alguns entendem que sua participação política deva se dar de maneira independente e crítica, manifestando seu desacordo com as formas de organizaçáo que se institucionalizam na forma de movimentos sociais instituídos e reconhecidos pelo Estado como interlocutores privilegiados. Essa presença expressiva colaborou para que em nossas rodas de conversa houvesse uma grande riqueza de temáticas específicas e de outras iniciativas de ação política.

Um dos participantes, certa vez, convidou o diretor do documentário Tobias 700 - a história de uma ocupação, com a proposta de projeção do filme seguida de debate. $O$ filme, que retratou trajetórias de famílias que realizaram uma ocupação em prédio do centro de Sáo Paulo, estimulou o debate sobre a luta pelo direito à moradia, sobre as políticas de moradia do Estado, inclusive aquelas ligadas à Política Nacional de Assistência Social. No debate, os albergues foram enfaticamente criticados, em especial na cidade de São Paulo, considerados como uma das únicas respostas à complexa problemática de moradia dessa parcela da populaçáo. Por outro lado, discutiu-se a importância de se fortalecer a compreensão de que moradia é um direito constitucional.

Nos encontros delimitava-se o momento dos informes (prática comum daqueles mais habituados a frequentar assembleias e fóruns), para troca de informaçôes sobre a agenda política, assim como sobre situações de violação de direitos e outras dificuldades de um cotidiano fortemente adverso. Sugestôes e orientaçóes surgiram da experiência dos participantes, como a indicação de espaços para denúncia de violaçôes e para a melhor organização política, como a Plenária Fala Rua, a Ouvidoria da População de Rua, o Ministério Público, entre outros. 
Em 2007, a solicitação para a construção de trabalho voltado para a formação política foi explicitada por líderes do MNPR/SP. Após um conjunto de discussóes, foi proposto um curso a ser coordenado por integrantes do Projeto Metuia e do MNPR-SP. Nosso principal desafio, naquele momento, foi a construção de um espaço de significação político aliado à formação (saber) de metodologias de abordagem em Terapia Ocupacional pautadas na troca e na produção de conhecimentos (aprofundamento de temáticas pertinentes e geradoras de consciência de direitos), agregando as pessoas e fortalecendo, igualmente, a comunicação, o laço social e, portanto, a própria organização do movimento.

$\mathrm{Na}$ medida em que as vivências, as metodologias e dinâmicas do PEC puderam ser debatidas, explicitando-se seus princípios norteadores, elas tornaram-se referências para os integrantes do MNPR e orientaram, também, a formulação de seu conteúdo programático e sua dinâmica: discussão conjunta de regras, resgate histórico do MNPR marcando o protagonismo de pessoas em situaçáo de rua e leitura crítica das dinâmicas sociais.

Desde a sua criação, em 2004, o MNPR produz açôes em conjunto com outras organizaçóes sociais ${ }^{11}$ no sentido de fortalecer o movimento como interlocutor do Estado na implementação de políticas públicas específicas. Com financiamento do Ministério do Desenvolvimento Social e Combate à Fome (MDS) e da UNESCO, desenvolveu em 2010, junto ao Instituto Pólis, o Projeto de Capacitação e Fortalecimento Institucional da População em Situação de Rua. Um dos resultados do projeto foi a confecção da cartilha para formação política Conhecer para Lutar (MOVIMENTO..., 2010), na qual o MNPR apresenta-se da seguinte forma:

Quando se fala em organizaçáo das pessoas em situação de rua logo surge a questão se elas reúnem condiçôes para se mobilizar coletivamente, já que estão submetidas a duras situações de vida. Nas ruas percebe-se isolamento e conflitos. No entanto, verifica-se que a própria sobrevivência exige organização e colaboração para cuidar da vida, como alimentação, proteção contra o frio e durante o sono. Neste sentido, o MNPR surgiu para enfrentar os riscos na rua. E mais, para repudiar o preconceito, a discriminação, as violações dos direitos humanos e também reivindicar políticas públicas que assegurem a dignidade desta populaçáa (MOVIMENTO..., 2010, p. 28).

Na cidade de Sáo Paulo ressaltamos a riqueza da experiência da Plenária Fala Rua tanto para a formação dos estudantes de graduação em Terapia
Ocupacional como para os militantes da luta por direitos sociais. Coordenada por membros do MNPR, constitui-se como um importante espaço político e de reflexão sobre políticas públicas direcionadas à população em situação de rua. Thais Miranda (2009), estagiária do Projeto Metuia, descreveu uma das assembleias na qual se definiu o dia de luta da população em situação de rua como forma de manter acesa a memória do assassinato de pessoas ocorrido na cidade de São Paulo em 2004.

[...] algumas falas indicaram que o massacre de pessoas em situação de rua que ocorreu em 2004 em São Paulo contribuiu para o fortalecimento do movimento, pois gerou a necessidade de maior união e organização, além de suscitar o debate e despertar grande indignação. Foi proposto que o dia 19 de agosto seja identificado como o dia de luta da população de rua, em homenagem aos mortos no massacre.

A proximidade do aniversário de cinco anos do massacre mobilizou uma série de discussóes dentro do PEC e de eventos na cidade de São Paulo, que foram articulados pelo Fórum Permanente de Acompanhamento das Políticas Públicas ${ }^{12}$. A agenda de eventos foi disponibilizada e discutida pelos participantes e alguns agenciamentos produzidos para favorecer a participação. Destacamos aqui a descrição de Valdir Pierote Silva (2009), estagiário do Projeto Metuia na época, que participou de uma parte dos eventos:

Durante os dias 14 a 20/8/2009 ocorreu em São Paulo evento em memória ao quinto ano do massacre ocorrido em agosto de 2004, quando 15 pessoas foram covardemente atacadas enquanto dormiam na regiáo central da cidade. Sete pessoas morreram e, até hoje, apenas os responsáveis pelo assassinato de uma das testemunhas do massacre foram presos. $\mathrm{O}$ lema do evento, portanto, não poderia ser outro senão: "Contra a impunidade e a favor da dignidade!” Em razão disso, o estágio em TO Social teve, ao longo de sua primeira semana, um cronograma excepcional, pois adotou o calendário do movimento da populaçáo em situação de rua, em memória aos cinco anos do massacre, como a atividade inicial da disciplina. Dentre uma série de atividades, participei do ato público na Praça da Sé, com a participação de grupos que saíram dos pontos do Centro onde ocorreu o massacre. Com a presença de várias entidades, jornalistas, vereadores e da secretária da assistência e desenvolvimento social, a vice-prefeita Alda Marco Antônio, o ato exigiu justiça e cobrou das autoridades o fim da repressão contra as pessoas em situação 
de rua na cidade de São Paulo. Além disso, foi queimada uma edição da revista Veja São Paulo da semana corrente, que, em reportagem sobre pessoas que pedem dinheiro nas ruas, insinua que a "mendicância" é um problema individual ou de caráter e náo um reflexo do sistema de produção vigente e da falta de políticas públicas para as pessoas em situação de vulnerabilidade.

O enfrentamento do preconceito, da discriminação e das constantes violaçóes dos direitos humanos incentivou a criação do Centro Nacional de Defesa dos Direitos Humanos da População em Situação de Rua e Catadores de Materiais Recicláveis, inaugurado em abril de 2011, em Belo Horizonte, com a perspectiva de abertura de mais três centros nas cidades de São Paulo, Curitiba e Salvador. Há que se destacar a implantação do Plano de Enfrentamento ao Uso do Crack e Outras Drogas, lançado em 2011 pelo governo federal, deflagrando e amplificando uma série de abusos $^{13}$ na açáo do Estado, especialmente na cidade de Sáo Paulo, e atingindo diretamente as pessoas em situação de rua. É necessário que diferentes setores da sociedade brasileira compreendam a heterogeneidade das pessoas em situação de rua, suas dificuldades e potencialidades.

O espaço da política evidenciou um circuito de fóruns, manifestações públicas, reuniōes, entre outros, dos quais o PEC participou ativamente ou foi nos quais foi contagiado por outros movimentos e iniciativas. Ainda que o PEC tenha se constituído em um serviço cultural e socioassistencial, ele, por sua dinâmica e forte apropriaçáo de seus membros participantes, tornou-se um pedaço (MAGNANI, 2002) para várias pessoas e mesmo para o movimento social organizado. Ou seja, transformou-se em um ponto de referência comum no qual estão em jogo sociabilidades que se estabelecem pelo manejo de símbolos e códigos comuns. Assim, partindo do espaço da cultura, foi possível tecer articulaçóes com a economia, a saúde, a assistência social e a política.

\section{Considerações finais}

As atividades no PEC foram definidas mediante negociaçôes, localizaçóes e vozes múltiplas. Elas só adquirem o caráter de atividade de significação, em nosso entender, quando e enquanto expressarem sentidos em contextos social e historicamente adequados, ou seja, quando possam permitir a construção de laços sociais, de redes de relações em espaços de significação, sejam eles culturais, políticos, econômicos ou outras possibilidades de articulação de identidades coletivas e de potencialidades singulares. Espaços e atividades em que pessoas e grupos podem tecer seus pedaços e desenhar seus circuitos, ressaltando que o sentido só pode se manifestar caso as atividades guardem inseparável a dimensão sociopolítica, cultural e afetiva de pessoas, de grupos e de comunidades (BARROS, 2004, p. 11-12).

Compreendemos assim a necessidade de desconstruir o conceito de atividade como instrumento em si, desconsiderando suas finalidades, seu contexto e os conflitos que emergem. Desse modo, as atividades

[...] não possuem significados fixos; formam-se constantemente múltiplos significados que se sobrepõem. Elas são expressōes das identidades e participam de processos que formam identidades. Sendo um processo relacional, é também, político [...] (BARROS; ALMEIDA; VECCHIA, 2004, p. 11).

A dialogia correspondeu a princípio norteador dos encontros no PEC e da presença do Projeto Metuia em açốes de pesquisa, ensino e extensão, implicando no exercício de redimensionar o saber técnico, por meio de processos nos quais se valoriza o saber de todos. Há que se estabelecer espaços de aprendizado mútuos nos quais, como destacou Barros (2004, p. 95), “[...] cada pessoa, cada grupo social/comunidade, a seu modo, juntos com outros, precisa descobrir as dimensôes e possibilidades da realidade".

A ação do terapeuta ocupacional, dessa forma, desenvolve-se na dialogia, na construção ou fortalecimento dos espaços de significação. A atividade nos desafia a potencializar a criaçáo expressa na liberdade e na experiência partilhada em relaçóes de troca de sentidos e possibilidades de ser no mundo. Há uma pluralidade de modos de conhecimento que precisam ser percebidos e valorizados. São valiosas para nós as reflexóes de Boaventura de Souza Santos sobre o papel da universidade e o lugar do conhecimento científico nas sociedades ocidentais. Santos (1999) analisou as crises das universidades modernas em termos de hegemonia e de legitimidade, apresentando uma pauta de transformaçóes necessárias para sua sobrevivência na chamada pós-modernidade. Dentre as pautas propostas, destacamos a importância da ruptura com a hegemonia do saber científico frente a outros saberes, como os do senso comum e a sabedoria popular. Além disso, tornou-se vital a criação de comunidades interpretativas nas quais as pessoas possam construir entendimentos do mundo a partir da interpretaçáo da realidade social que lhes diz respeito. 
Desenham-se, assim, inúmeras possibilidades de iniciativas relativas às exigências de ensinoaprendizagem (estudantes de graduação em Terapia Ocupacional), formação técnica, formação artística, formação política, enfim, de tudo que requer qualificação. Mas, muito além disso, ensaiamos a consciência coletiva diante de temas que definem nosso tempo, de que o trabalho de leitura do real em perspectivas múltiplas valoriza criativamente as formas de racionalidade, as experiências singulares e sua elaboração e a percepção de que juntos aprendemos uns com os outros.

\section{Referências}

AUGÉ, M. Não-lugares: introdução a uma antropologia da supermodernidade. São Paulo: Papirus, 1994.

BARROS, D. D. Terapia ocupacional social: o caminho se faz ao caminhar. Revista de Terapia Ocupacional da USP, São Paulo, v. 15, n. 3, p. 90-97, 2004. http://dx.doi. org/10.11606/issn.2238-6149.v15i3p90-97

BARROS, D. D.; ALMEIDA, M. C.; VECCHIA, T. C. Terapia ocupacional social: diversidade, cultura e saber técnico. Revista de Terapia Ocupacional da USP, São Paulo, v. 18, n. 3, p. 128-134, 2007. http://dx.doi. org/10.11606/issn.2238-6149.v18i3p128-134

BOUVIER, P. Le lien social. Paris: Gallimard, 2005.

BRASIL. Constituição (1988). Constituiçấo da República Federativa do Brasil: promulgada em 5 de outubro de 1988. Diário Oficial da República Federativa do Brasil, Poder Executivo, Brasília, 5 out. 1988. Seção 1. Disponível em: <www.senado.gov. br/legislacao/const/>. Acesso em: 9 jan 2012.

CERTEAU, M. A invenção do cotidiano: artes de fazer. 3. ed. Petrópolis: Vozes, 1998.

ELIAS, N. A sociedade dos individuos. Rio de Janeiro: Jorge Zahar, 1994.

FERREIRA, T. P. Palavras inacadêmicas. São Paulo: Projeto Metuia, 2009.

FÓRUM DE PRÓ-REITORES DE EXTENSÃO DAS UNIVERSIDADES PÚBLICAS BRASILEIRAS E SESU/ MEC. Plano Nacional de Extensão Universitária. ed. atual. Natal: MEC, 2000/2001. Disponível em: <www20.fcm. unicamp.br/extensão/arquivos/pne.pdf >. Acesso em: 17 fev. 2012.

FREIRE, P. Educação como prática da liberdade. 5. ed. Rio de Janeiro: Paz e Terra, 1975.
FREIRE, P. Pedagogia do oprimido. Rio de Janeiro: Paz e Terra, 1987a.

FREIRE, P. Pedagogia da autonomia: saberes necessários à prática educativa. São Paulo: Paz e Terra, 1987b.

GALVANI, D.; BARROS, D. D. Pedro e seus circuitos na cidade de São Paulo: religiosidade e situação de rua. Interface: Comunicação, Saúde, Educação, Botucatu, v. 14, n. 35 , p. $767-779$, 2010. http://dx.doi.org/10.1590/ S1414-32832010005000022

GHIRARDI, M. I. G. Percursos de pesquisa e estratégias de ensino no campo da assistência em terapia ocupacional. Revista de Terapia Ocupacional da USP, São Paulo, v. 22, n. 3, p. 216-20, 2011. http://dx.doi.org/10.11606/ issn.2238-6149.v22i3p216-220

GRAMSCI, A. Os intelectuais e a organização da cultura. 9. ed. Rio de Janeiro: Civilizaçáo Brasileira, 1995.

LETRAS em Cena. Quem somos: apresentação. 2013. Disponível em: <http://www.letrasemcena.art.br/html/ quemsomos_apresenta.aspx?PageID $=1>$. Acesso em: 01 abr. 2013.

LÉVY, P. L'intelligence collective: pour une anthropologie du cyberespace. Paris: La Découverte, 1997.

MAGNANI, J. G. C. De perto e de dentro: notas para uma etnografia urbana. Revista Brasileira de Ciências Sociais, São Paulo, v. 17, n. 49, p. 11-29, 2002. http:// dx.doi.org/10.1590/S0102-69092002000200002

MIRANDA, T. C. Terapia ocupacional no campo social: estágios supervisionados III. São Paulo, 2009. Diário de campo. Mimeo.

MOVIMENTO NACIONAL DA POPULAÇÃO DE RUA - MNPR. Cartilha de Formação do Movimento Nacional da População de Rua. Brasília: MDS, UNESCO, Instituto Pólis, 2010. Disponível em: <http://www.polis. org.br/uploads/887/887.pdf>. Acesso em: 30 out. 2013. NARDO, M. Terapia ocupacional no campo social: estágios supervisionados III. São Paulo, 2008. Diário de campo. Mimeo.

ROTELLI, F. Luomo e la cosa. In: COMMEMORAZIONE PUBBLICA DI FRANCO BASAGLIA, 1983, Trieste. Trieste: Instituto Gramsci, 1983. Disponível em: <http:// www.triestesalutementale.it/basaglia/uomo_e_cosa.htm>. Acesso em: 9 set. 2012.

SANTOS, B. S. Da ideia de universidade à universidade de ideias. In: SANTOS, B. S. Pela mão de Alice: o social e o político na pós-modernidade. São Paulo: Cortez, 1999. p. $187-233$.

SILVA, V. P. Terapia ocupacional no campo social: estágios supervisionados III. São Paulo, 2009. Diário de campo. Mimeo.

\section{Contribuição dos Autores}

Todas as autoras foram responsáveis pela reflexão, análise e redação das ideias desenvolvidas no artigo.

\section{Notas}

1 "Noi facciamo della pratica, prima della pratica e poi della teoria. Non facciamo prima della teoria e poi della pratica perché questo sarebbe un cammino molto più reazionario di quanto voi non possiate pensare; la teoria è l'a priori scientifico: del vecchio 
pensiero scientifico [...]. Non avessi accettato questo rischio avrei riciclato inevitabilmente la teoria antica, quella dei testi e dei manuali da cui sono venuto. Avrei soddisfatto una forma di narcisismo intellettuale, avrei tradotto le nuove esperienze dentro un codice e un linguaggio che sarebbe rimasto lo stesso." Franco Basaglia apud Rotelli (1983). Tradução das autoras.

${ }^{2}$ A organização, filiada à International Network of Street Paper (INSP), é responsável pela edição da Revista Ocas, que é comprada pelo vendedor por $\mathrm{R} \$ 1,00$ e vendida por $\mathrm{R} \$ 4,00$ exclusivamente nas ruas das cidades de Sáo Paulo e Rio de Janeiro.

${ }^{3}$ Organização não governamental que desenvolve projetos com adultos em situação de rua na cidade de São Paulo. É responsável, entre outras atividades, pela produçáo do jornal O Trecheiro. Outras informaçóes no endereço: http://www. rederua.org.br

${ }^{4} \mathrm{O}$ texto foi inspirado no diário de campo da estudante Marcela Nardo.

${ }^{5}$ Espaço cultural da Secretaria de Cultura do Estado de São Paulo.

${ }^{6}$ O Letras em Cena "[...] é um projeto de leituras dramáticas que acontece desde 2006 no Grande Auditório do MASP, em São Paulo, todas as segundas-feiras. [...] Sua principal vocação é promover a leitura e aproximar o grande público da leitura de peças teatrais, contos e poesias” (LETRAS EM CENA, 2013).

${ }^{7}$ Há um convênio Metuia-USP/Casa das Áfricas desde 2005, originado em projeto para a realização de açôes em uma comunidade rural de Aiuruoca (Minas Gerais) e formaçáo em Terapia Ocupacional Social.

${ }^{8}$ As rodas de conversa e debates tiveram vários temas e foram inspiradas nos círculos de cultura de Paulo Freire (FREIRE, 1975).

9 Número 171, 2008.

${ }^{10} \mathrm{O}$ projeto recebeu colaboraçóes dos pesquisadores Robert Cabanes e Cleisa Rosa.

${ }^{11}$ Para citar algumas, em especial na cidade de São Paulo: Pastoral do Povo de Rua, Organização de Auxílio Fraterno, Centro de Mídia Independente, Associação Rede Rua, Centro Gaspar Garcia de Direitos Humanos, Fórum Permanente de Acompanhamento das Políticas Públicas, Fórum de Debates sobre a População em Situação de Rua, Movimento Nacional dos Catadores de Materiais Recicláveis, entre outras.

${ }^{12}$ Conjunto de fóruns, organizaçóes e movimentos sociais.

${ }^{13}$ A Coordenação do Fórum Nacional de Defesa de Direitos para a População em Situação de Rua e a Representação da Sociedade Civil no Comitê de Acompanhamento e Monitoramento da Política Nacional da População em Situação de Rua, ambas com representação de militantes do MNPR, assinaram carta de repúdio às açóes violentas citadas, a qual foi endereçada à presidente da república Dilma Roussef. Ela explicita, ainda, uma série de articulaçóes e conquistas que tiveram o MNPR como protagonista e que colaboram, inclusive legalmente, para a exigência da implementação de políticas públicas e na garantia de direitos. 